\title{
Microstructure Evolution and Shaping of Friction Stir Lap Welded Dissimilar Magnesium Alloy Joint
}

\author{
Tielong $\mathrm{Li}^{*}{ }^{* 1,2}$ and Zhenshan Wang ${ }^{3}$ \\ ${ }^{I}$ Tianjin Key Laboratory of Advanced Joining Technology, School of Materials Science and Engineering, Tianjin \\ University, Tianjin 300072, China \\ ${ }^{2}$ Mechanical and Electrical Engineering Department, Yuncheng University, Yuncheng, Shanxi, 044000, China \\ ${ }^{3}$ Shanxi Wenxi Silver Magnesium Industry Co, LTD, Yuncheng, Shanxi, 043800, China
}

\begin{abstract}
Friction stir lap welding (FSLW) experiment has been conducted on 3mm thick AZ80 extruded sheet and $2.3 \mathrm{~mm}$ thick AZ31B rolled sheet. The influence of the shape of the taper thread mixing head on microstructure has been discussed. Pores forming, hooked defects, interface migration, tissue distribution have been analyzed. The organization of both sides of nugget zone (NZ) is arranged diagonally above, due to the corresponding resultant force along the thread of pin. NZ was collided to form a cascade "onion ring" by plastic microstructure rotating with thread of the pin and dropping from concave of mixing head conical body. Cavity defect was concerned with the poor deformation of AZ80 magnesium alloy placed underneath and relevant organization collision.
\end{abstract}

Keywords: Dissimilar magnesium alloy, friction stir lap welding, interface migration, metallurgical structure, the flow of organizations.

\section{INTRODUCTION}

There are many lap joints in aerospace, shipbuilding and light-rail structures. Due to lightweight, low energy consumption, green remanufacturing requirements of various industries, magnesium alloys are often chosen for lap joints [1]. Fusion welding of magnesium alloys have a variety of defects that are difficult to be eliminated, which influence the mechanical properties of the joint. Friction stir lap welding (FSLW), a solid-state bonding, can be used as an alternative approach [2]. Chen et al. [3] applied FSLW to join AZ31B magnesium alloy and aluminum alloy, and they found a transition zone between the welding zone and the bottom. Naik et al. [4] showed that FSLW parameters affect hook size of AZ31B magnesium alloy joint where the joint has been fractured. Jana et al. [5] studied the influence of mixing head shape on the performance of magnesium alloy and steel lap joint. Xing [6, 7] demonstrated that the height of interface migration increased with the increase of plunge depth of shoulder and interface migration of the retreating side was higher than the advancing side in FSLW joint of aluminum alloy. Wang et al. [8] discussed the influence of the length of the needle on hook type size and joint performance. Al-badour et al. [9] established a finite element model to simulate dissimilar alloy FSLW of different mixing needle. Jagadeesha [10] friction stir butt welded dissimilar aluminum and magnesium alloys at low speed. There is no unified understanding of the complex plastic flow of microstructures in friction stir welding. However, it is

*Address correspondence to this author at the Tianjin Key Laboratory of Advanced Joining Technology, School of Materials Science and Engineering, Tianjin University, Tianjin 300072, China; Tel: 13753918248; E-mail: 378269309@qq.com believed that the shape of the mixing head, rotational speed, and the weld speed play an important role. In this paper, interface shape and migration of FSLW joint of the dissimilar magnesium alloy have been discussed, microstructure and defects of different parts of joint have been analyzed, and the plastic flow of microstructure in the process of welding forming has been discussed.

\section{EXPERIMENTAL PROCEDURE}

Test materials were provided by Shanxi Wenxi Silver Magnesium Industry Co., LTD. Material types are given in Table 1, composition and performance of the material are given in Table 2.

FSW-RL31-010 type friction stir welding machine was used, with right-lateral taper thread mixing head made of 4Cr5MoSiV1: shoulder diameter was $10 \mathrm{~mm}$, and stirring needle length, $2.8 \mathrm{~mm}$. Mixing head tilt Angle is $2.5^{\circ}$ in the direction of welding, and plunge depth of shoulder, $0.2 \mathrm{~mm}$. AZ31B was placed on the AZ80, as shown in Fig. (1). FSLW was conducted at a rotation rate being $800 \mathrm{rpm}$, and welding speed being $210 \mathrm{~mm} / \mathrm{min}$ along the rolling and extrusion direction. All the surfaces to be welded were cleaned and the oxide film was not removed. After welding, cross section perpendicular to the welding direction was chosen for microstructure observation. The samples were cut, mechanically grounded, polished and then etched with a solution consisting of $1 \mathrm{~g}$ picric acid, $2.5 \mathrm{ml}$ acetic acid, 2.5 $\mathrm{ml} \mathrm{H}_{2} \mathrm{O}$ and $17.5 \mathrm{ml}$ ethanol. The microstructure was examined by the OLYMPUS 2GX51 optical microscopy $(\mathrm{OM})$. In the weld, Vickers hardness values of different red imaginary line as shown in Fig. (3) were conducted using 
Table 1. Main components and mechanical properties of magnesium alloy.

\begin{tabular}{|c|c|c|c|c|c|c|}
\hline Alloy & Thickness (mm) & Form of Organization & Forming way & Length Direction & Class & Norms (mm) \\
\hline \hline AZ31B & 2.3 & Extrusion & Squeezing & Squeezing direction & Thin plate & $200 \times 400$ \\
\hline AZ80 & 3 & Cast & Rolling & Rolling direction & Thin plate & $200 \times 400$ \\
\hline
\end{tabular}

Table 2. Composition and performance of magnesium alloy.

\begin{tabular}{|c|c|c|c|c|c|c|c|}
\hline Alloy & \multicolumn{5}{|c|}{ Mass Fraction/\% } & Maximum Force/KN & $\begin{array}{c}\text { Elongation } \\
\text { Rate } \%\end{array}$ \\
\hline AZ80 & $7.8 \sim 9.2$ & $0.15 \sim 0.50$ & $0.2 \sim 0.8$ & $\leq 0.3$ & Bal & 27.01 & 10.2 \\
\hline
\end{tabular}

432SVD Vickers hardness tester. The advancing side and retreating side respectively are marked as AS and RS.

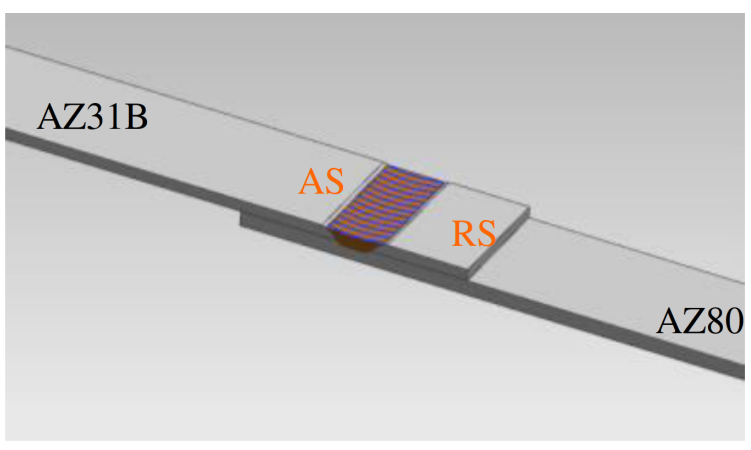

Fig. (1). Drawing of sample.

\section{RESULTS AND DISCUSSION}

\subsection{Macro Morphology}

The weld surface is relatively smooth without grooves and wrinkling defects. However, both sides of welding have the flash as shown in Fig. (2).

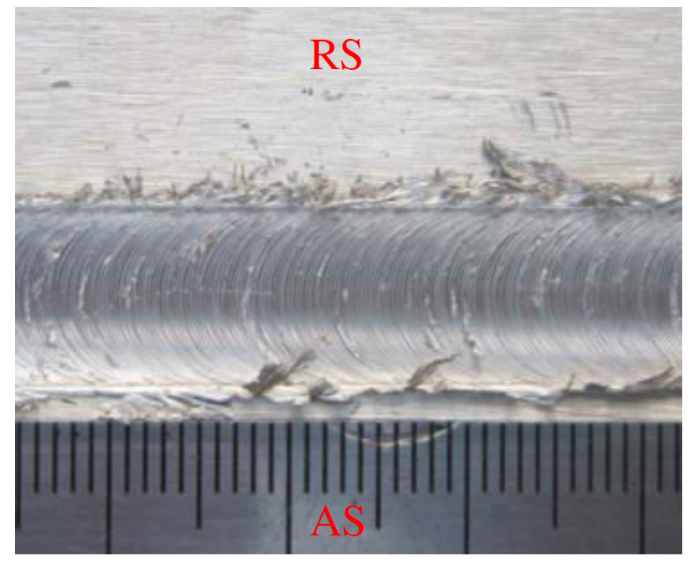

Fig. (2). Macrograph of friction stir welded joint.

Lap interface of the two horizontal plates, such as the stir needle, whose length is greater than thickness of the top plate rotating, was broken by the lower end of mixing needle into two plate lap interface, and when the stir needle moves forward, in the rear of the stir needle, dense welds were formed. At both sides of Weld, that is the original lap interface bending to the upper plate and extending into the upper evolved migration interface, is DFB of the weld cross section as shown in Fig. (3). In the meantime, it was observed that the height of the retreating side is higher than the advancing side. This is consistent with the literature [6]. Center of joint has a big tunnel defect, which is 364 microns wide, 195 microns high.

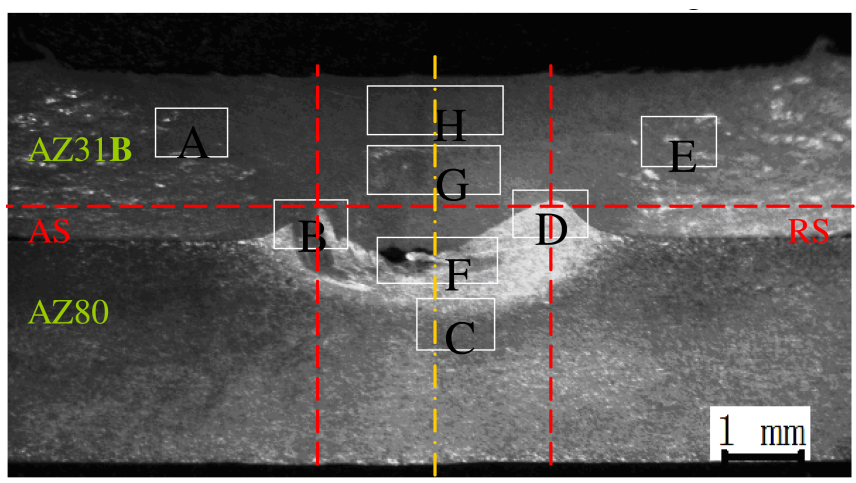

Fig. (3). Overviews of transverse sections.

\subsection{Microstructure Evolution}

As-cast AZ31B microstructure contains dendritic segregation and texture due to roll forming. The grain sizes are different on inside and outside grain sizes of plate, as shown in Fig. (4). Microstructures near the plate surface are relatively small, but are large in the middle plate. Extrusion state dynamic recrystallization of AZ80 magnesium alloy sheet occurs, forming texture. The magnesium alloy substrate, $\alpha$ phase, precipitates the $\beta$ phase, namely the $\mathrm{Mg}_{17} \mathrm{Al}_{12}$ phase, leading to refinement and texture reinforcement. As shown in Fig. (5), deep black organizations of the grain boundary make the $\beta$ phase, and the rest, $\alpha$ phase. With the aluminum content increase, grain boundary precipitates more compounds.

Heat affected zone, mechanical heat-affected zone, nugget zone were marked as HAZ, TMAZ, NZ respectively. Each photo of Fig. (6) corresponds to A, B, C, D, E, F, G, H of Fig. (3) respectively denoting upper plate boundary figure of AS, two plate boundary figure of AS, boundary figure of underface, two plate boundary figure of RS, upper plate 

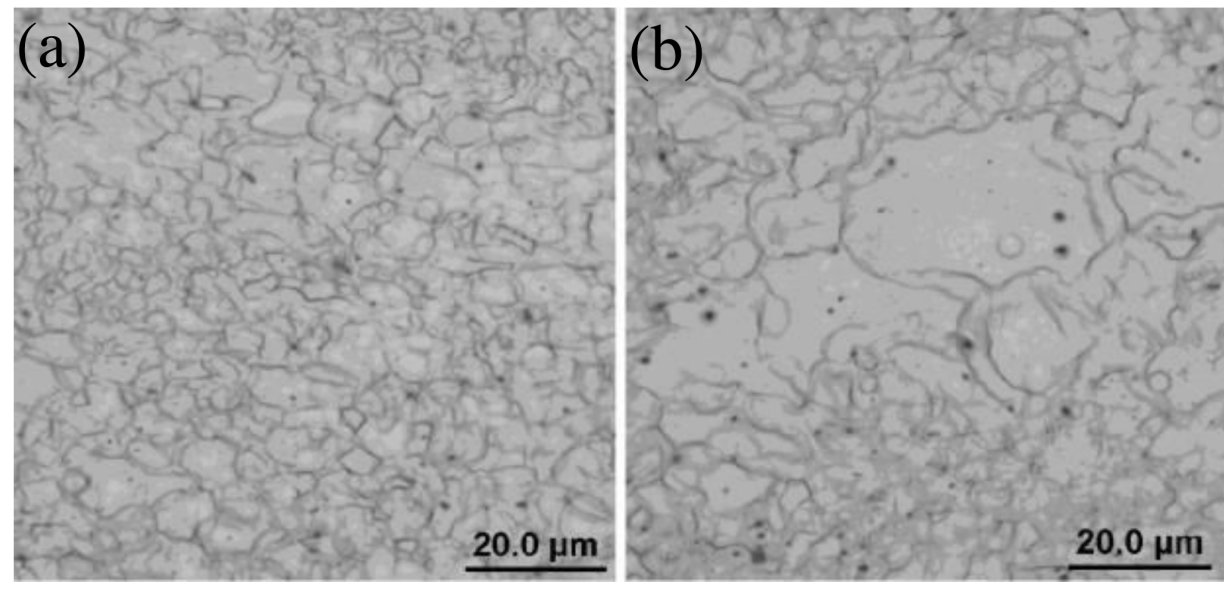

Fig. (4) Metallographs (a) Near the surface of the plate (b) In the middle plate.

boundary figure of RS, commixture NZ, middle NZ, and upside NZ.

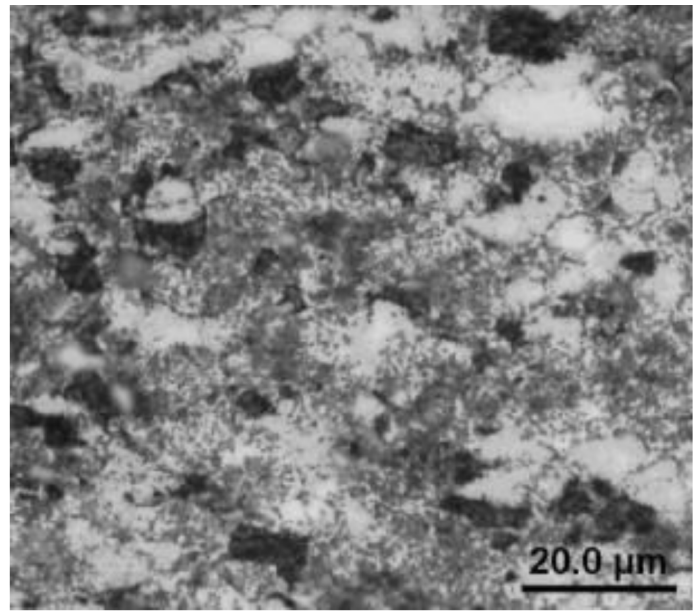

Fig. (5) Metallographs.

Microstructures of NZ are small, but the upside NZ microstructures are smaller and more uniform than the middle NZ. TMAZ and HAZ of the upper and the lower plates are different. In the lower plate, TMAZ recrystallization is almost complete, $\beta$ strengthening phase will be dissolved, and the HAZ organization heating will respond, as shown in Fig. (7); their base metal is organizations of AZ80. AZ31B TMAZ part recrystallize to flatten the organization, and HAZ grow up slightly as shown in Fig. (6a, e).

\subsection{Micro-Hardness}

Due to the uneven grain and compressing, HV0.1 value of as-cast AZ31B rolling sheet is $58 \sim 69$. HV0.1 value of extrusion state AZ80 sheet, is $75 \sim 83$ because of texture and big extrusion pressure. HV0.1 value of AZ80 NZ is $52 \sim 63$ [11].

As shown in Fig. (3), because the measured position deviating from the plate boundary lie in upward $0.4 \mathrm{~mm}$,

both sides of NZ are AZ31B magnesium alloy. As shown in Fig. (8a), hardness value of NZ fluctuates ups and downs, may be due to association with AZ80 and AZ31B mutual crisscross overlap, it is slightly larger than the AZ31B hardness value. Difference in hardness value of RS is greater than the AS. Hardness values of RS have maximum and minimum hardness values. The minimum value lying in the interface is close to AZ80 hardness value because AZ80 magnesium alloy has been rotated to interface where the D location of Fig. (3) is located.

On both sides of welding, TMAZ is suffered stir friction heat and extrusion of the plastic microstructures. The predominated intenerate mechanisms of TMAZ during hot deformation are dynamic recovery and partly growing up. This is equivalent to annealing. Microstructures of TMAZ are bulky or crushed grains, and bigger than the parent metal grains. So its hardness values showing a downward trend near NZ are lower than those of parent metal. Microstructures of HAZ subjected to thermal cycling began to respond similarly, by slightly growing up. Its hardness is lower than the one of parent metal.

As shown in the Fig. (8b), hardness value of RS is higher than one of AS in NZ, whereas hardness value of RS outside $\mathrm{NZ}$ in the lower plate is smaller, hardness values of RS and AS are both lower than AZ80 BM's. Hardness value from the closest top surface in the upper plate is slightly larger because it cooled down even faster, and then down dip because it is AZ31B NZ's and again rise because AZ80 spins up, forming commixture NZ's value, and then drop due to passing into TMAZ and HAZ of AZ80, gradually transit to the AZ80 parent metal's values.

\subsection{Discussion}

Upside NZ value from the original BM as-cast microstructure as shown in Fig. (4a), which is comparatively fine after rolling, is smaller after full shoulder friction, extrusion and recrystallization. The size of the microstructure about $1 \mathrm{~mm}$ above the weld surface is fine as shown at $\mathrm{H}$ location of Fig. (3), which illustrates that upside $\mathrm{NZ}$ is only flowing over the upper surface.

When welding the horizontal continuous lap interface between two plates because rotation of the stir needle makes the lap interface into the upper plate, it is broken into waves curve. On both sides of the weld, as shown in Fig. (3), the 


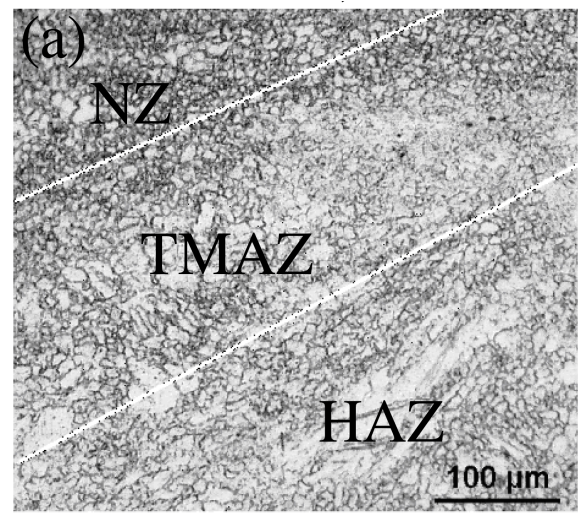

(a) Upper plate boundary figure of AS

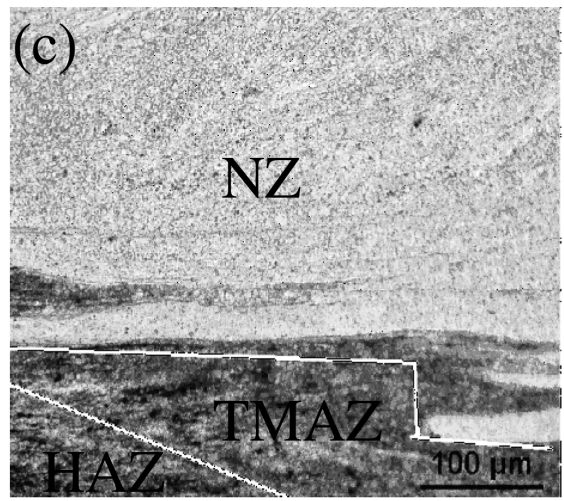

(c) Boundary figure of underface

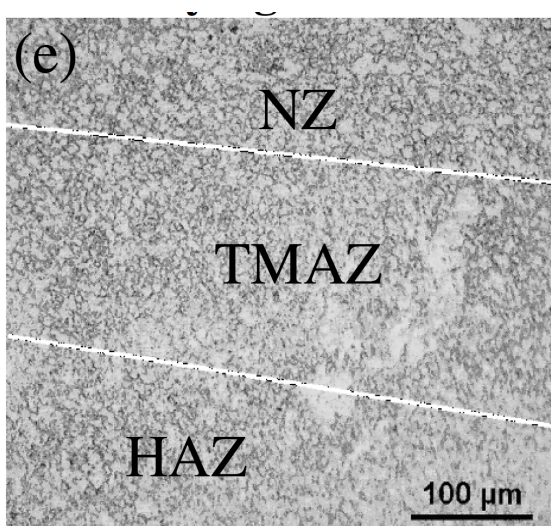

(e) Upper plate boundary figure of RS

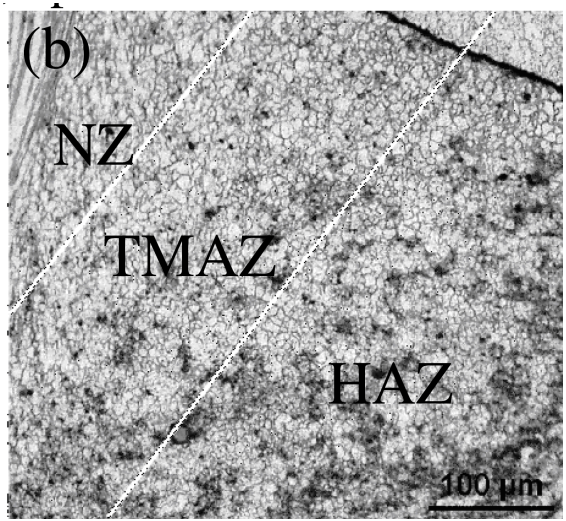

(b) Two plate boundary figure of AS

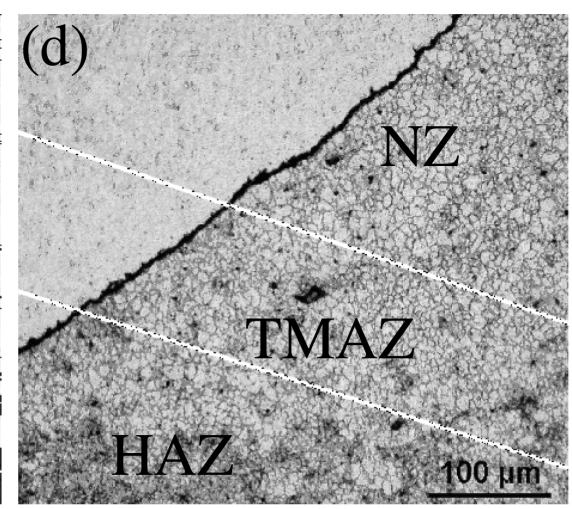

(d) Two plate boundary figure of RS

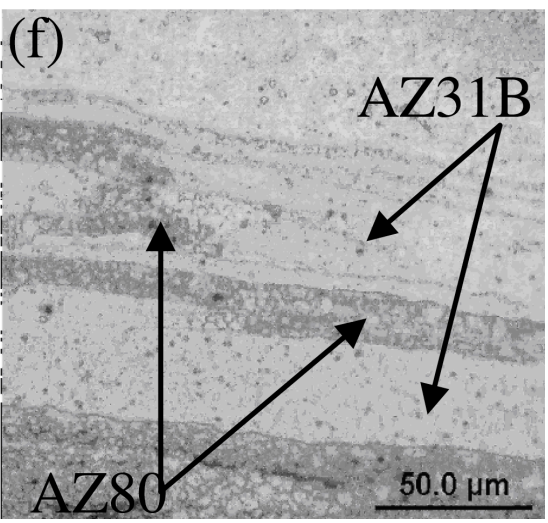

(f) Commixture NZ

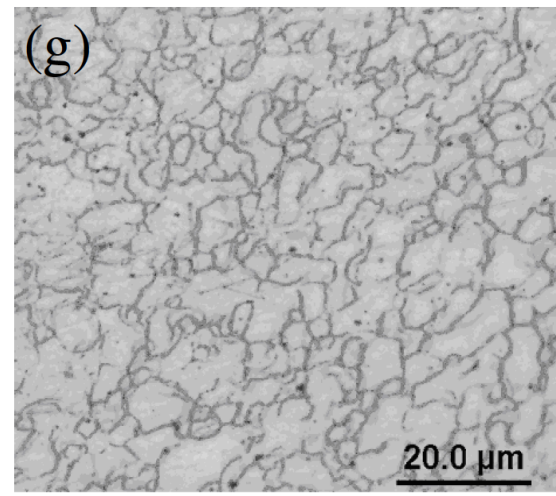

(g) Middle NZ

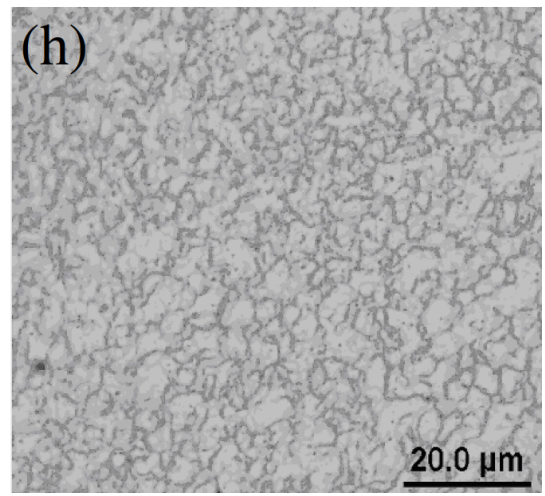

(h) Upside NZ

Fig. (6). Metallographs of each point in Fig. (3). 


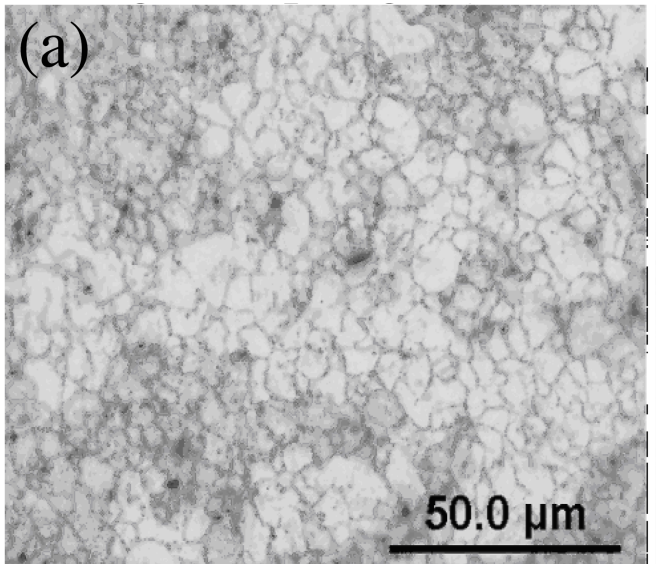

(a) TMAZ of the lower plate

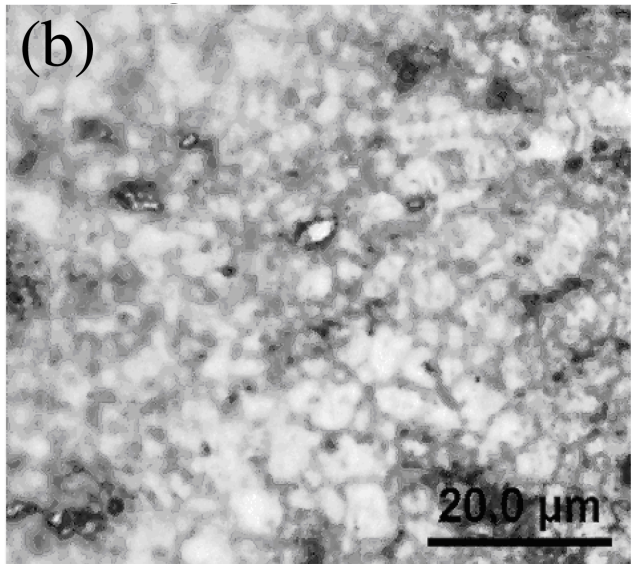

(b) HAZ of the lower plate

Fig. (7). Metallographs.

interface migration at place D in RS is high, radius of curvature large and is extended to the weld center, and the interface migration at place B in AS shows a sharp corner, but under the microscopic figure it shows cut off hooked defects as shown in Fig. (9). It can produce stress concentration, that becomes an obvious crack origination, a latent defect deciding on the size of the load bearing the welded joint.

(a) Micro-hardness of cross sectional joint

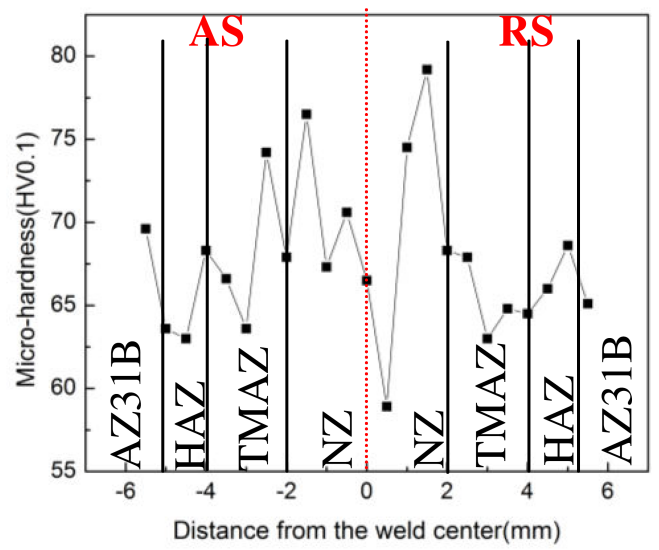

(b) Micro-hardness of both sides of NZ

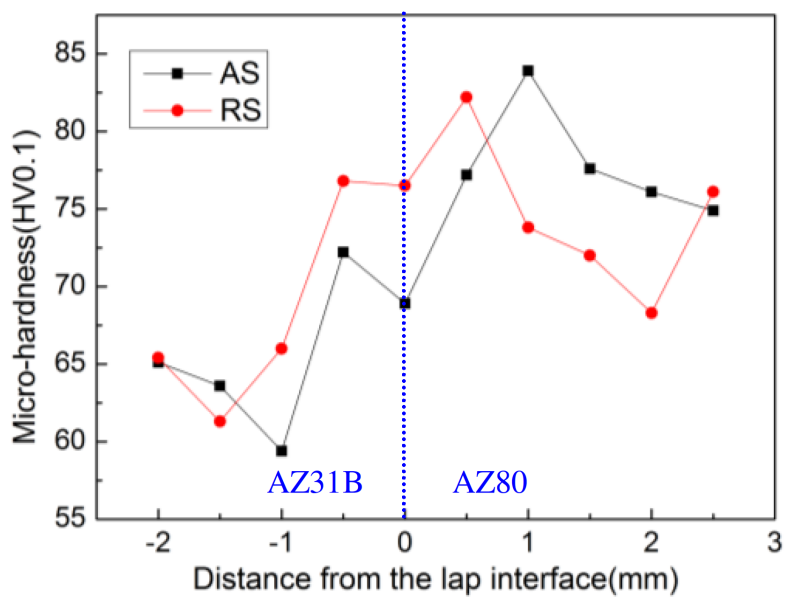

Fig. (8). Micro-hardness of cross sectional joint.

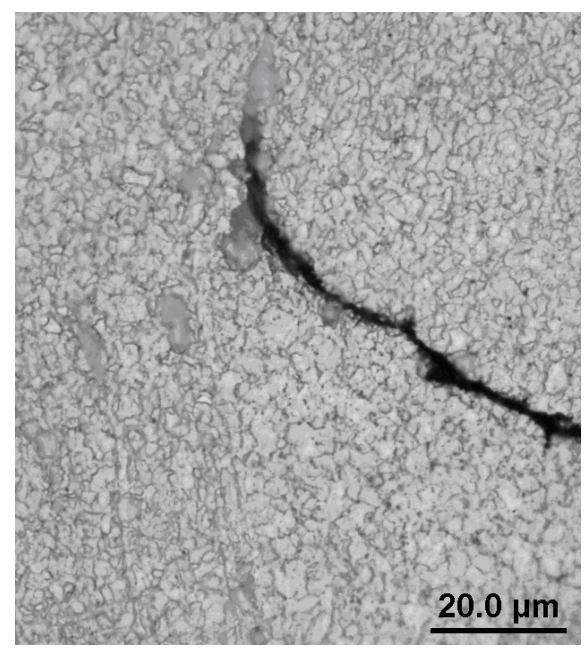

Fig. (9). Metallographs.

F location of Fig. (3) is the weld center in which there are boundaries of two kinds of materials, generating "onion ring" structures as can be seen from the Fig. (6f) in which a layer of AZ80 folds another layer of AZ31B, namely nugget of the region is formed by nugget of two kinds of parent metals mixed alternately.

The plastic microstructure of the rear part of thread of the stirring tool is affected by upside support force of surface of thread $(\mathrm{N})$, gravity $(\mathrm{G})$, friction (f), and rotating centrifugal force (F), as shown in Fig. (10). The forces are summed up into a resultant extrusion force on the surrounding organization, that is inclining upward force along the thread. In Figs. (3 and 6), microstructure deformation trends in RS and AS are all upward diagonally, which further verifies the above hypothesis. Once the microstructure leaves the thread without upside support force, coupled with the downside pressure of the shoulder, the total force of microstructure is applied downside diagonally. When the mixing head moves forward, the cavity is left behind it. Because the cavity was closed around microstructures, the cavity has the effect of the inside suction. The inside cone under the shoulder contains a number of plastic microstructures which are produced by friction between the shoulder and workpiece, with characteristics of fluid. Plastic microstructure of cone which underwent continuous extrusion caused by 
surrounding microstructures, the downside pressure of the shoulder and the inner suction of the cavity, must move downside to fill the cavity left by the mixing tool moving forward. Plunge depth of the shoulder is $0.2 \mathrm{~mm}$, which fully ensures the tightness of the cavity and plenty of plastic microstructures of the inner cone to fill down the cavity. Angle of mixing head inclining to the welding direction is $2.5^{\circ}$, which ensures that the cavity gets smooth from top to bottom. Once the plastic microstructure spinning with the stirring tool along the thread direction leave the thread, they can meet, crash with those of inner cone, then drop down, and deposit backward. In the lower NZ, two types of microstructures crush alternately, form commixture microstructures. And downward, the pressure force affected the shaft shoulder and the centrifugal force of rotating microstructures decreased, so that this downside deposit force is smaller. This may be one of the reasons for the weld center as being holes. Another possible cause of the existence of a cavity is that poor plastic deformation of AZ80 needs more heat input, but the end of stirring tool generates limited heat and heat conduction from top is insufficient.

Interface migration of AS is low and B location of Fig. (3) contains AZ31B microstructures, may be due to plastic microstructure of the inner cone deposited first with downward pressure and the cavity suction. On the other hand, plastic microstructures are swiveling more along the thread because of small rotation speed and resistance of the surrounding microstructures, than on reaching the advancing side. Boundary of interface microstructures shown in D location of Fig. (3), is distinct. Microstructures under the interface are mainly AZ80's, because plastic microstructures of the inner cone of mixing tool drop less.

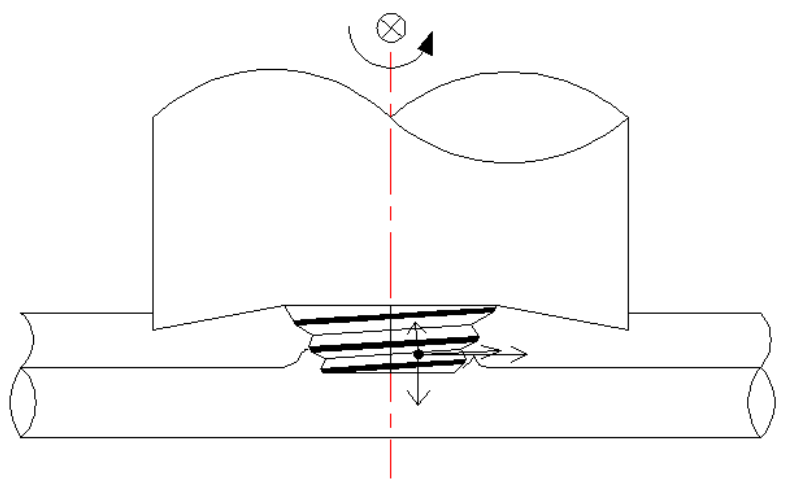

Fig. (10). The stress analysis diagram $(\oplus$ denotes inward welding direction).

\section{CONCLUSION}

(1) Upside and middle NZ were mainly AZ31B microstructures. Lower NZ was alternative mixture of $\mathrm{AZ} 80$ and AZ31B microstructures.
(2) Interface migration of AS is lower than RS. This is likely because plastic microstructure of the cone suffered stress of surrounding microstructures and shoulder, suction of cavity, deposit more at the location; plastic microstructures rotating with stirring tool along the thread drop less.

(3) Hardness value of NZ varies significantly; hardness value of NZ in RS is higher than those of AS.

(4) Sharp corner of the interface of AS may be a potential crack initiator.

(5) Tunnel defects form because the deposition force of plastic microstructure is small and the AZ80 plastic deformation ability is poor.

\section{CONFLICT OF INTEREST}

The authors confirm that this article content has no conflict of interest.

\section{ACKNOWLEDGEMENTS}

The authors acknowledge the financial support for this work by the National Nature Science Foundation of China (No.50775159). We owe sincere thanks to Dr. Lei Cui for the support of the experiment and the paper.

\section{REFERENCES}

[1] Xu H, Liu JA, Xie SS. Magnesium Alloy Fabrication and Processing Technology. Metallurgical Industry Press: Beijing 2007, pp. 22-93.

[2] Thomas WM, Needlham JC, Dawes CJ. Friction stir butt welding Great Briton, 9125978.8. December 1991.

[3] Chen YC, Nakata K. Friction stir lap joining aluminum and magnesium alloys. Scripta Materialia 2008; 58: 433-443

[4] Naik BS, Chen DL, Cao X. Microstructure and fatigue properties of a friction stir lap welded magnesium alloy. Metallurgy Mat Transact A 2013; 44(8): 3732-3746

[5] Jana S, Hovanski Y, Grant GJ. Effect of tool feature on the joint strength of dissimilar friction stir lap welds. Friction Stir Welding and Processing VI, 2011. DOI: 10.1002/978111806 2302.Ch25

[6] Xing L, We1 P, Song X. Influence of plunge depth of shoulder on mechanical properties of friction stir lap joints. Transact China Welding Institut 2013; 34(3): 15-19

[7] Wei P, Xing L, Xu WP. Influence of plunge depth of shoulder on interface migration of friction stir lap welds. J Mat Eng 2011; 6: 43-47.

[8] Wang M, Zhang H, Zhang J. Effect of pin length on hook size and joint properties in friction stir lap welding of 7B04 Aluminum alloy. J Mat Eng Perform 2014; 23(5): 1881-1886.

[9] Al-badour F, Merah N, Shuaib A. Thermo-mechanical finite element model of friction stir welding of dissimilar alloys. Int $\mathbf{J}$ Adv Manufact Technol 2014; 72(5): 607-617

[10] Jagadeesha CB. Dissimilar friction stir welding between aluminum alloy and magnesium alloy at a low rotational speed. Mat Sci Eng A 2014; 616(8): 55-62.

[11] Li TL, Yang XQ, Wang ZS. Analysis on hardness of friction stir butt-welded AZ80 alloy. Hot Working Technol 2013; 42(9): 201204. 